ఠ

\title{
nab-Paclitaxel/carboplatin in elderly patients with advanced squamous non-small cell lung cancer: a retrospective analysis of a Phase III trial
}

This article was published in the following Dove Press journal: Drug Design, Development and Therapy

\author{
Cesare Gridelli' \\ Tianlei Chen ${ }^{2}$ \\ Amy Ko ${ }^{2}$ \\ Mary E O'Brien ${ }^{3}$ \\ Teng Jin Ong ${ }^{4}$ \\ Mark A Socinski ${ }^{5}$ \\ Pieter E Postmus ${ }^{6}$ \\ 'Division of Medical Oncology, \\ S. G. Moscati Hospital, Avellino, Italy; \\ ${ }^{2}$ Biostatistics, Celgene Corporation,

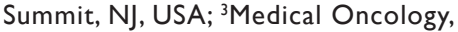 \\ Royal Marsden Hospital, London, UK; \\ ${ }^{4}$ Medical Affairs, Celgene Corporation, \\ Summit, NJ, USA; ${ }^{5}$ Lung Cancer \& \\ Esophageal Cancer, Florida Hospital \\ Cancer Institute, Orlando, FL, USA; \\ ${ }^{6}$ Pulmonary Diseases, Clatterbridge \\ Cancer Center, Liverpool, UK
}

Correspondence: Cesare Gridelli Division of Medical Oncology, S.G. Moscati Hospital, Contrada Amoretta, 83100 Avellino, Italy

Tel +390825203426

Email cgridelli@libero.it
Background: Limited data on elderly patients with squamous advanced non-small cell lung cancer (NSCLC) preclude optimal treatment. Here, we report the outcomes of a retrospective analysis of a subset of patients $\geq 70$ years with squamous histology from the Phase III trial that evaluated nab-paclitaxel/carboplatin vs paclitaxel/carboplatin.

Patients and methods: Patients with stage IIIB/IV NSCLC received (1:1) nab-paclitaxel $100 \mathrm{mg} / \mathrm{m}^{2}$ on days 1,8 , and 15 or paclitaxel $200 \mathrm{mg} / \mathrm{m}^{2}$ on day 1 , both with carboplatin area under the curve $6 \mathrm{mg} \times \mathrm{min} / \mathrm{mL}$ on day 1 every 3 weeks. The primary endpoint was independently assessed overall response rate as per the Response Evaluation Criteria in Solid Tumors v1.0. Secondary endpoints included progression-free survival, overall survival, and safety.

Results: Sixty-five patients $\geq 70$ years with squamous histology were included (nab-paclitaxel/ carboplatin, $n=35$; paclitaxel/carboplatin, $n=30$ ). nab-Paclitaxel/carboplatin vs paclitaxel/ carboplatin, respectively, resulted in an overall response rate of $46 \%$ vs $20 \%$ (response rate ratio, 2.29, $P=0.029$ ) and a median overall survival of 16.9 vs 8.6 months (hazard ratio, 0.50, $P=0.018$ ). No difference was observed in median progression-free survival (5.7 months for both). Incidences of grade $3 / 4$ neutropenia ( $50 \%$ vs $63 \%$ ), leukopenia ( $29 \%$ vs $37 \%$ ), fatigue ( $3 \%$ vs $13 \%)$, and peripheral neuropathy ( $3 \%$ vs $13 \%$ ) were lower, but those of thrombocytopenia (21\% vs $10 \%)$ and anemia $(21 \%$ vs $7 \%)$ were higher with nab-paclitaxel/carboplatin vs paclitaxel/carboplatin.

Conclusion: nab-Paclitaxel/carboplatin was efficacious and tolerable in patients $\geq 70$ years with squamous NSCLC. These results build upon prior analyses, indicating that nab-paclitaxel/ carboplatin is effective for this difficult-to-treat patient subgroup.

Keywords: taxanes, comorbidities, age, chemotherapy, histology

\section{Introduction}

Although elderly patients account for a large percentage of those diagnosed with lung cancer (median age at diagnosis is 70 years), treatment of this population remains challenging and the median age at death is 72 years. ${ }^{1,2}$ Treatment of elderly patients or those with comorbidities may be complicated by perceptions of increased susceptibility to toxicity. ${ }^{3}$ Patients $\geq 70$ years are also underrepresented in clinical trials, resulting in few tested treatment options for this patient population. ${ }^{4,5}$ Single-agent therapy was once considered a standard of care for elderly patients with advanced non-small cell lung cancer (NSCLC); however, evidence has demonstrated that platinum-doublet chemotherapy can also benefit these patients. ${ }^{6-9}$ Thus, platinum-doublet therapy is recommended as first-line treatment for elderly patients with NSCLC. According to the European Society for Medical Oncology, platinum-based chemotherapy is preferred 
for elderly patients, including those with an Eastern Cooperative Oncology Group performance status of $2 .{ }^{8}$ The National Comprehensive Cancer Network does not provide specific recommendations for elderly patients with NSCLC, but platinum doublets are recommended for all age groups as first-line treatment of advanced NSCLC. ${ }^{10}$ The recent advent of immuno-oncology agents has improved the treatment landscape of NSCLC, but treatment options for elderly patients remain limited. To date, there has been no randomized immuno-oncology study devoted specifically to the elderly population, with results available only from retrospective analyses of the main trials. Therefore, the impact of these agents on elderly patients with NSCLC has yet to be fully determined. The programmed death ligand-1 (PD-L1) inhibitor pembrolizumab was recently added to the recommended treatments for first-line therapy by the National Comprehensive Cancer Network for patients (all ages) with advanced NSCLC and PD-L1-positive and epidermal growth factor receptor (EGFR)-, anaplastic large-cell lymphoma kinase (ALK)-, ROS1-negative/unknown tumors. ${ }^{10}$

The relationship between histology and treatment outcomes in elderly patients with advanced NSCLC remains to be determined. Two separate analyses of Survival, Epidemiology, and End Results data - one that included $>316,000$ patients with lung cancer and the other one that included $>51,000$ patients with stage IV NSCLC - indicated that at least $20 \%$ of patients $\geq 70$ years had squamous NSCLC. ${ }^{11,12}$ Although results likely vary by treatment type and line of therapy, patients with squamous histology may have worse outcomes compared with patients with other histologic subtypes; therefore, improved treatment options for this patient subset are necessary. ${ }^{12}$ Some agents are not indicated or recommended in patients with squamous NSCLC, and patients with squamous histology are not likely to have sensitizing EGFR mutations, further limiting their treatment options. ${ }^{10}$ Chemotherapy has been shown to improve outcomes in patients with squamous histology, ${ }^{14,15}$ making it an important option for these patients. Taken together, a treatment regimen that improves outcomes in patients with advanced squamous NSCLC who are $\geq 70$ years is important for improving care in this patient subset.

nab-Paclitaxel, a microtubule inhibitor, is a nanoparticle formulation of paclitaxel bound to human albumin. Results from the Phase III registrational trial of nab-paclitaxel/ carboplatin in advanced NSCLC indicate that this regimen may be an effective and safe treatment option for patients $\geq 70$ years with squamous NSCLC. ${ }^{13}$ In a subset analysis of elderly patients, nab-paclitaxel/carboplatin demonstrated a nearly 20-month median overall survival
(OS; 19.9 months), which was almost double that observed with paclitaxel/carboplatin (10.4 months). ${ }^{5}$ Treatment with nab-paclitaxel/carboplatin also resulted in a significant improvement in the overall response rate (ORR) compared with paclitaxel/carboplatin in the subgroup of patients with squamous histology (41\% vs $21 \% ; P<0.001) .{ }^{14}$ No new safety signals were observed with nab-paclitaxel/carboplatin treatment relative to the intent-to-treat (ITT) population.

This exploratory analysis of the Phase III trial evaluated the efficacy and safety of nab-paclitaxel/carboplatin vs paclitaxel/carboplatin in elderly patients with advanced squamous NSCLC. Although this analysis focused on patients $\geq 70$ years, some data for patients $\geq 60$ and $\geq 65$ years are provided for comparison.

\section{Patients and methods}

Patients, study design, and methods of the Phase III trial (NCT00540514) $)^{13}$ were described previously. Briefly, patients with histologically or cytologically confirmed stage IIIB or IV NSCLC, measurable disease by Response Evaluation Criteria in Solid Tumors v1.0, and an Eastern Cooperative Oncology Group performance status of $0-1$ were eligible. Patients were randomized 1:1 to receive first-line nab-paclitaxel $100 \mathrm{mg} / \mathrm{m}^{2}$ on days 1,8 , and 15 plus carboplatin area under the curve (AUC) $6 \mathrm{mg} \times \mathrm{min} / \mathrm{mL}$ on day 1 or paclitaxel $200 \mathrm{mg} / \mathrm{m}^{2}$ on day 1 with carboplatin AUC $6 \mathrm{mg} \times \mathrm{min} / \mathrm{mL}$ on day 1 - both given every 3 weeks. Stratification factors included disease stage (IIIB vs IV), age ( $<70$ vs $\geq 70$ years), sex (male vs female), histology (squamous vs adenocarcinoma vs other), and geographic region (North American vs Russia/Ukraine vs Japan vs Australia). Completion of $\geq 6$ cycles of treatment was encouraged, and treatment could continue in the absence of disease progression and unacceptable toxicity at the investigator's discretion. All relevant ethical approvals from institutional review boards/independent ethics committees were obtained prior to study commencement (see Supplementary material for details). Informed consent was obtained from all patients prior to study entry.

The primary endpoint was independently assessed ORR (complete and partial response) as per Response Evaluation Criteria in Solid Tumors v1.0. Secondary endpoints included progression-free survival (PFS; independent review), OS (overall survival followed up for 18 months posttreatment), and safety. Tumor assessment via computed tomography scans occurred every 6 weeks until tumor progression. Efficacy was evaluated in all randomized patients (ITT population); safety was evaluated in all patients who received $\geq 1$ dose of the study drug. 


\section{Statistical methods}

The comparison of response rates between regimens was assessed using the chi-square test. PFS and OS were described using Kaplan-Meier methods. Differences in Kaplan-Meier curves were assessed using the log-rank test stratified by geographic region and histology of primary diagnosis. Treatment differences in OS were also analyzed by age groups (from $\geq 60$ to $\geq 70$ years in 1 -year increments) using a log-rank test stratified by geographic region to examine the age-related trend. Hazard ratios (HRs) and their CIs were estimated using a stratified (region) Cox proportional hazard model.

\section{Results \\ Patients}

Baseline characteristics of patients with squamous histology stratified by age ( $\geq 60, \geq 65$, and $\geq 70$ years) are summarized in Table 1. Baseline characteristics were comparable across the age groups, regardless of treatment, with a few exceptions. A higher percentage of patients aged $\geq 60$ years was from Eastern Europe, whereas a higher percentage of patients aged $\geq 70$ years was from North America or the Asia/Pacific region. Within each age group, baseline characteristics between treatment arms were generally well balanced. In patients aged $\geq 70$ years, a higher percentage of patients treated with nab-paclitaxel/carboplatin was from the Asia/Pacific region and had never smoked, whereas a higher percentage of patients treated with paclitaxel/carboplatin was white, from Eastern Europe, and had smoked and were still smoking.

\section{Efficacy results}

Median OS increased with age in patients treated with nab-paclitaxel/carboplatin (11.8, 13.9, and 16.9 months for patients $\geq 60$, $\geq 65$, and $\geq 70$ years, respectively), but remained stable with paclitaxel/carboplatin treatment ( $\sim 9$ months; Table 2 ). In patients aged $\geq 70$ years with squamous histology, treatment with nab-paclitaxel/ carboplatin resulted in a significantly longer OS vs paclitaxel/ carboplatin (median, 16.9 vs 8.6 months; HR 0.50; 95\% CI, 0.275-0.896; $P=0.018$; Figure 1A). However, PFS was similar between treatment arms in elderly patients (median, 5.7 months for both groups; HR 0.68; 95\% CI, 0.347-1.339; $P=0.267$; Figure 1B). ORR increased 2-fold with nabpaclitaxel/carboplatin vs paclitaxel/carboplatin treatment, and the difference was statistically significant ( $46 \%$ vs $20 \%$; response rate ratio, 2.29; 95\% CI, 1.025-5.095; $P=0.029$; Table 2). More patients in the nab-paclitaxel/carboplatin arm than in the paclitaxel/carboplatin arm had deeper radiological responses, as measured by the best change from baseline

Table I Baseline characteristics of patients $\geq 60, \geq 65$, and $\geq 70$ years with squamous NSCLC

\begin{tabular}{|c|c|c|c|c|c|c|}
\hline \multirow[t]{2}{*}{ Characteristic } & \multicolumn{2}{|l|}{$\geq 60$ years } & \multicolumn{2}{|l|}{$\geq 65$ years } & \multicolumn{2}{|l|}{$\geq 70$ years } \\
\hline & $\begin{array}{l}\text { nab-P/C } \\
(n=106)\end{array}$ & $\begin{array}{l}P / C \\
(n=|| 0)^{a}\end{array}$ & $\begin{array}{l}\text { nab-P/C } \\
(n=67)\end{array}$ & $\begin{array}{l}P / C \\
(n=70)^{b}\end{array}$ & $\begin{array}{l}\text { nab-P/C } \\
(n=35)\end{array}$ & $\begin{array}{l}P / C \\
(n=30)^{c}\end{array}$ \\
\hline Age, median (range), years & $67(60-8 I)$ & $67(60-84)$ & $70(65-8 I)$ & $69(65-84)$ & $72(70-8 I)$ & $72(70-84)$ \\
\hline \multicolumn{7}{|l|}{ Sex, n (\%) } \\
\hline Male & $91(86)$ & $94(85)$ & $59(88)$ & $60(86)$ & $30(86)$ & $26(87)$ \\
\hline Female & $15(14)$ & $16(15)$ & $8(12)$ & $10(14)$ & $5(14)$ & $4(13)$ \\
\hline \multicolumn{7}{|l|}{ Race, n (\%) } \\
\hline White & $89(84)$ & $103(94)$ & $53(79)$ & $66(94)$ & $26(74)$ & $28(93)$ \\
\hline Black or African American & $5(5)$ & $2(2)$ & $5(7)$ & $\mathrm{I}(\mathrm{I})$ & $3(9)$ & 0 \\
\hline Other & $12(11)$ & $5(5)$ & $9(13)$ & $3(4)$ & $6(17)$ & $2(7)$ \\
\hline \multicolumn{7}{|l|}{ ECOG PS, n (\%) } \\
\hline 0 & $24(23)$ & $19(17)$ & $16(24)$ & $12(17)$ & $7(20)$ & $8(27)$ \\
\hline I & $82(77)$ & $91(83)$ & $51(76)$ & $58(83)$ & $28(80)$ & $22(73)$ \\
\hline \multicolumn{7}{|l|}{ Region, n (\%) } \\
\hline Eastern Europe & $74(70)$ & $83(75)$ & $4 I(6 I)$ & $48(69)$ & $17(49)$ & $17(57)$ \\
\hline North America & $23(22)$ & $22(20)$ & $19(28)$ & $19(27)$ & $13(37)$ & II (37) \\
\hline Asia/Pacific & $9(8)$ & $5(5)$ & $7(10)$ & $3(4)$ & $5(14)$ & $2(7)$ \\
\hline Australia/New Zealand & 0 & 0 & 0 & 0 & 0 & 0 \\
\hline \multicolumn{7}{|l|}{ Smoking status, n (\%) } \\
\hline Never smoked & $16(15)$ & $16(15)$ & $11(16)$ & $9(13)$ & $7(20)$ & $3(10)$ \\
\hline Smoked and quit smoking & $35(33)$ & $38(35)$ & $26(39)$ & $27(39)$ & $14(40)$ & $11(38)$ \\
\hline Smoked and currently smokes & $55(52)$ & $54(50)$ & $30(45)$ & $33(48)$ & $14(40)$ & $15(52)$ \\
\hline
\end{tabular}

Notes: ${ }^{a} n=108$ for smoking status; ${ }^{b} n=69$ for smoking status; ${ }^{c} n=29$ for smoking status.

Abbreviations: ECOG PS, Eastern Cooperative Oncology Group performance status; nab-P/C, nab-paclitaxel/carboplatin; NSCLC, non-small cell lung cancer; $\mathrm{P} / \mathrm{C}$, paclitaxel/carboplatin. 
Table 2 Efficacy summary for patients $\geq 60, \geq 65$, and $\geq 70$ years with squamous NSCLC (randomized patients)

\begin{tabular}{|c|c|c|c|c|c|c|}
\hline \multirow[t]{2}{*}{ Outcome } & \multicolumn{2}{|c|}{$\geq 60$ years } & \multicolumn{2}{|c|}{$\geq 65$ years } & \multicolumn{2}{|c|}{$\geq 70$ years } \\
\hline & $\begin{array}{l}\text { nab-P/C } \\
(n=106)\end{array}$ & $\begin{array}{l}P / C \\
(n=I 10)\end{array}$ & $\begin{array}{l}\text { nab-P/C } \\
(n=67)\end{array}$ & $\begin{array}{l}P / C \\
(n=70)\end{array}$ & $\begin{array}{l}\text { nab-P/C } \\
(n=35)\end{array}$ & $\begin{array}{l}P / C \\
(n=30)\end{array}$ \\
\hline ORR, \% & 45 & 25 & 46 & 26 & 46 & 20 \\
\hline $\begin{array}{l}\text { Ratio of ORR }(95 \% \mathrm{Cl}) \\
P \text {-value }\end{array}$ & \multicolumn{2}{|c|}{$\begin{array}{c}\mathrm{I} .85(\mathrm{I} .25 \mathrm{I}-2.72 \mathrm{I}) \\
0.00 \mathrm{I}\end{array}$} & \multicolumn{2}{|c|}{$\begin{array}{c}1.80(1.120-2.892) \\
0.012\end{array}$} & \multicolumn{2}{|c|}{$\begin{array}{c}2.29(1.025-5.095) \\
0.029\end{array}$} \\
\hline Median OS, months & 11.8 & 9.5 & 13.9 & 9.4 & 16.9 & 8.6 \\
\hline $\begin{array}{l}\mathrm{HR}(95 \% \mathrm{Cl}) \\
P \text {-value }\end{array}$ & \multicolumn{2}{|c|}{$\begin{array}{c}0.70(0.510-0.961) \\
0.027\end{array}$} & \multicolumn{2}{|c|}{$\begin{array}{c}0.62(0.4 I I-0.928) \\
0.019\end{array}$} & \multicolumn{2}{|c|}{$\begin{array}{c}0.50(0.275-0.896) \\
0.018\end{array}$} \\
\hline Median PFS, months & 5.7 & 5.7 & 5.7 & 5.7 & 5.7 & 5.7 \\
\hline $\begin{array}{l}\mathrm{HR}(95 \% \mathrm{Cl}) \\
P \text {-value }\end{array}$ & \multicolumn{2}{|c|}{$\begin{array}{c}0.71(0.499-1.014) \\
0.059\end{array}$} & \multicolumn{2}{|c|}{$\begin{array}{c}0.70(0.443-1.102) \\
0.121\end{array}$} & \multicolumn{2}{|c|}{$\begin{array}{c}0.68(0.347-1.339) \\
0.267\end{array}$} \\
\hline
\end{tabular}

Abbreviations: HR, hazard ratio; nab-P/C, nab-paclitaxel/carboplatin; NSCLC, non-small cell lung cancer; ORR, overall response rate; OS, overall survival; P/C, paclitaxel/ carboplatin; PFS, progression-free survival.

in target lesion diameters (Figure 2); this observation corroborates the results in all patients with squamous NSCLC, regardless of age (Figure S1).

\section{Treatment exposure}

Taxane dose intensity was higher with nab-paclitaxel/ carboplatin vs paclitaxel/carboplatin treatment in patients with squamous histology who were aged $\geq 70$ years $(76.69$ vs $63.16 \mathrm{mg} / \mathrm{m}^{2} /$ week; Table 3 ). The median number of cycles administered was similar between the treatment groups (five and six for nab-paclitaxel/carboplatin and paclitaxel/ carboplatin, respectively).

\section{Safety}

In patients aged $\geq 70$ years with squamous histology, grade 3/4 adverse events were mainly hematologic (Table 4). nab-Paclitaxel/carboplatin vs paclitaxel/carboplatin treatment

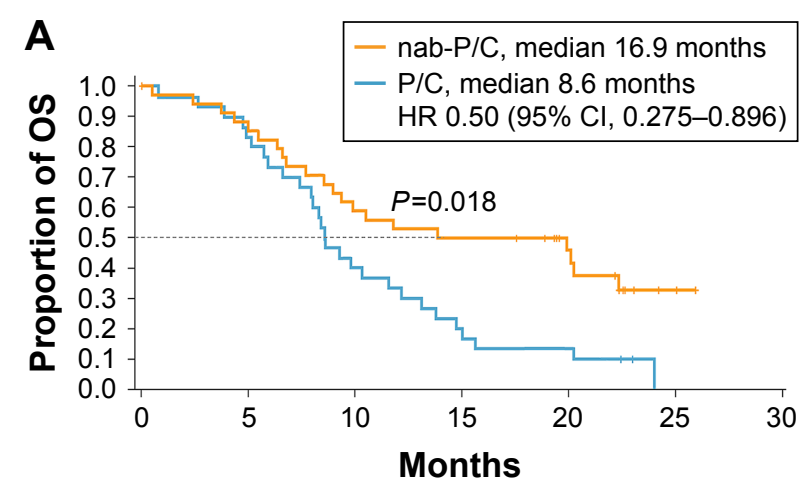

\section{Pts at risk}

$\begin{array}{rllllll}\text { nab-P/C } & 35 & 29 & 20 & 17 & 11 & 2 \\ \text { P/C } & 30 & 25 & 12 & 6 & 4 & 0\end{array}$

resulted in less grade 3/4 neutropenia (50\% vs 63\%), leukopenia ( $29 \%$ vs $37 \%$ ), and fatigue ( $3 \%$ vs $13 \%$ ), but more thrombocytopenia ( $21 \%$ vs $10 \%)$ and anemia (21\% vs $7 \%$ ). Treatment-related grade $3 / 4$ peripheral neuropathy occurred in $3 \%$ and $13 \%$ of patients treated with nab-paclitaxel/ carboplatin and paclitaxel/carboplatin, respectively.

\section{Discussion}

In this exploratory analysis of the Phase III registrational trial, first-line nab-paclitaxel/carboplatin was efficacious and tolerable in patients $\geq 70$ years with squamous NSCLC compared with paclitaxel/carboplatin. These results support the role of nab-paclitaxel/carboplatin as a treatment option in NSCLC and may help address an unmet need - the lack of data on clinical outcomes in elderly patients with squamous NSCLC.

The efficacy and safety results from this analysis are consistent with the data reported separately for the elderly

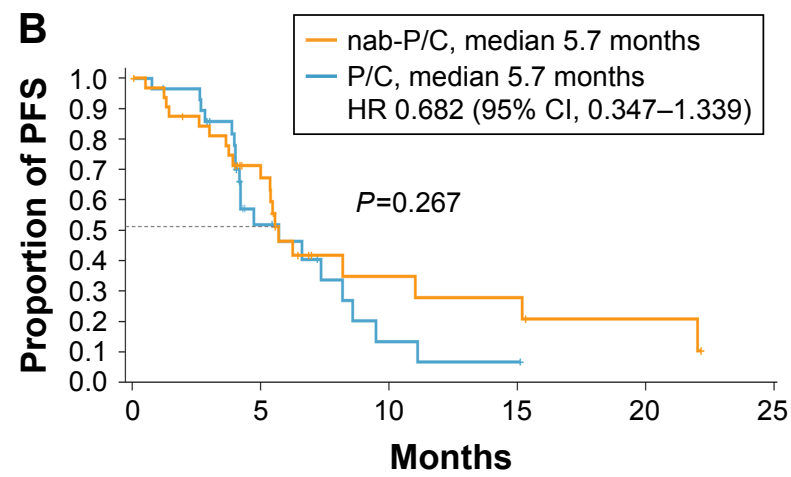

\begin{tabular}{|c|c|c|c|}
\hline Pts at risk & & & \\
\hline nab-P/C 35 & 17 & 5 & 4 \\
\hline $\mathrm{P} / \mathrm{C} 30$ & 10 & 2 & 1 \\
\hline
\end{tabular}

Figure I (A) OS and (B) PFS in patients $\geq 70$ years with squamous NSCLC.

Abbreviations: HR, hazard ratio; nab-P/C, nab-paclitaxel/carboplatin; NSCLC, non-small cell lung cancer; OS, overall survival; P/C, paclitaxel/carboplatin; PFS, progression-free survival. 


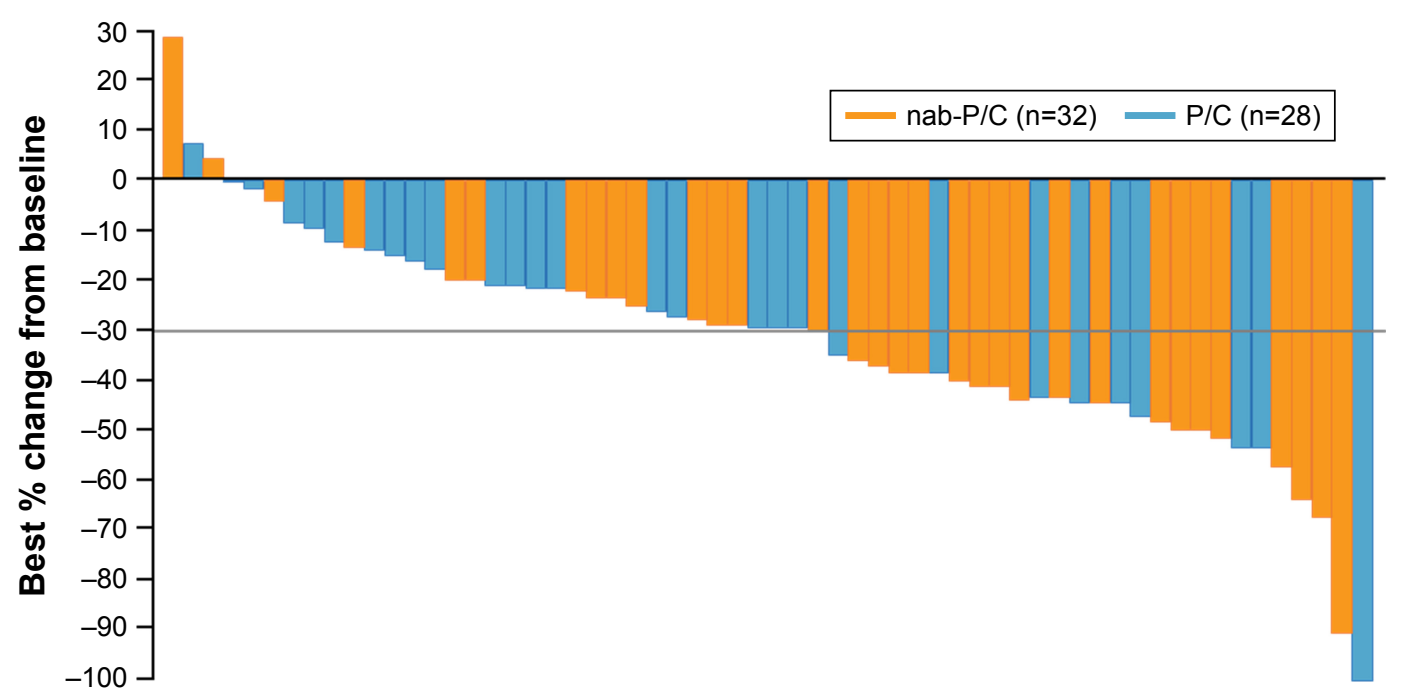

Figure 2 Best change from baseline in the total length of target lesions in patients $\geq 70$ years with squamous NSCLC. Abbreviations: nab-P/C, nab-paclitaxel/carboplatin; NSCLC, non-small cell lung cancer; P/C, paclitaxel/carboplatin.

and squamous populations in previous publications from the Phase III trial. ${ }^{5,13,14}$ In the Phase III trial, the ORR in patients $\geq 70$ years was numerically higher with nab-paclitaxel/ carboplatin vs paclitaxel/carboplatin ( $34 \%$ vs $24 \%, P=0.196$ ); OS was significantly improved (median, 19.9 vs 10.4 months, $P=0.009$ ), and PFS trended in favor of nab-paclitaxel/ carboplatin (median, 8.0 vs 6.8 months, $P=0.134$ ) in these patients. ${ }^{5}$ In a subset analysis that assessed outcomes by histology (regardless of age), patients with squamous histology experienced a significantly higher ORR with nab-paclitaxel/ carboplatin than with paclitaxel/carboplatin ( $41 \%$ vs $24 \%$, $P<0.001) .{ }^{14}$ nab-Paclitaxel/carboplatin treatment also resulted in a numerically longer OS vs paclitaxel/carboplatin in these patients (median, 10.7 vs 9.5 months, $P=0.310$ ), but no difference in PFS was observed between the regimens. Safety findings reported in these patient populations were similar to those of the ITT population. ${ }^{13}$ Furthermore,

Table 3 Treatment exposure in patients $\geq 70$ years with squamous NSCLC

\begin{tabular}{lll}
\hline Parameter & $\begin{array}{l}\text { nab-P/C } \\
(\mathbf{n = 3 4 )}\end{array}$ & $\begin{array}{l}\mathbf{P} / \mathbf{C} \\
(\mathbf{n}=\mathbf{3 0})\end{array}$ \\
\hline $\begin{array}{l}\text { Median number of cycles } \\
\text { administered }\end{array}$ & 5 & 6 \\
$\begin{array}{l}\text { Median dose intensity } \\
\text { Taxane, } \mathrm{mg} / \mathrm{m}^{2} / \text { week }\end{array}$ & 76.69 & \\
$\quad$ Carboplatin, AUC/week & 1.45 & 63.16 \\
$\begin{array}{l}\text { Median cumulative dose } \\
\text { Taxane, } \mathrm{mg} / \mathrm{m}^{2}\end{array}$ & $1,175.0$ & 1.89 \\
$\quad$ Carboplatin, AUC & 26.3 & $1,200.0$ \\
\hline
\end{tabular}

Abbreviations: AUC, area under the curve; nab-P/C, nab-paclitaxel/carboplatin; NSCLC, non-small cell lung cancer; P/C, paclitaxel/carboplatin. two separate retrospective analyses of the Phase III trial indicated that nab-paclitaxel/carboplatin was effective and tolerable in patients with renal impairment and diabetes. ${ }^{16,17}$ These findings are relevant to the elderly population because this patient population is often at higher risk of comorbidities.

Platinum-doublet therapy, including nab-paclitaxel/ carboplatin, is the preferred first-line option for both elderly and squamous populations. ${ }^{8-10}$ However, few studies have assessed platinum-doublet therapy in the elderly/squamous patient subgroup. A subset analysis of a Phase III trial evaluating paclitaxel/carboplatin vs vinorelbine or gemcitabine monotherapy $(\mathrm{n}=451)$ demonstrated that first-line platinum-doublet chemotherapy was associated with a survival benefit compared with monotherapy in elderly patients with non-adenocarcinoma histology (mainly squamous, but included "other" non-adenocarcinoma histologies). ${ }^{18}$ In a

Table 4 Selected safety data for patients $\geq 70$ years with squamous NSCLC (treated patients)

\begin{tabular}{|c|c|c|c|c|}
\hline \multirow[t]{2}{*}{ Adverse events, \% } & \multicolumn{2}{|l|}{$\begin{array}{l}\text { nab-P/C } \\
(n=34)\end{array}$} & \multicolumn{2}{|l|}{$\begin{array}{l}P / C \\
(n=30)\end{array}$} \\
\hline & Grade I/2 & Grade 3/4 & Grade I/2 & Grade $3 / 4$ \\
\hline \multicolumn{5}{|l|}{ Hematologic } \\
\hline Neutropenia & 32 & 50 & 23 & 63 \\
\hline Leukopenia & 59 & 29 & 50 & 37 \\
\hline Thrombocytopenia & 32 & 21 & 53 & 10 \\
\hline Anemia & 79 & 21 & 90 & 7 \\
\hline \multicolumn{5}{|l|}{ Nonhematologic } \\
\hline Fatigue & 32 & 3 & 20 & 13 \\
\hline $\begin{array}{l}\text { Peripheral } \\
\text { neuropathy }\end{array}$ & 50 & 3 & 60 & 13 \\
\hline
\end{tabular}

Abbreviations: nab-P/C, nab-paclitaxel/carboplatin; NSCLC, non-small cell lung cancer; P/C, paclitaxel/carboplatin. 
subset analysis of a Phase III trial of patients with metastatic squamous NSCLC $(n=1,093)$, the addition of necitimumab to platinum-doublet chemotherapy did not demonstrate superior OS compared with platinum-doublet treatment in patients $\geq 70$ years. ${ }^{19}$ Although, historically, prospective data on platinum doublets in elderly patients with squamous NSCLC are lacking, a recent Phase I/II dose-finding study prospectively evaluated first-line biweekly gemcitabine/ carboplatin treatment in patients $\geq 70$ years with advanced or metastatic squamous NSCLC $(n=69) .{ }^{15}$ In the Phase I part of the study, the maximum tolerated dose was not reached, and dose-limiting toxicities included grade 5 renal toxicity and grade 3 thrombocytopenia (both in the same patient); one death occurred (renal failure). In the Phase II part of the study, biweekly gemcitabine/carboplatin was administered at the last dose level tested (gemcitabine 1,100 mg/m², carboplatin AUC 2.5). The ORR (primary endpoint) was 36\% (95\% CI, $23.0 \%-48.8 \%$ ), the median PFS was 6.7 months $(95 \% \mathrm{CI}$, 4.2-8.8 months), and the median OS was 13.3 months (95\% CI, 7.1-19.6). Grade 3/4 neutropenia and thrombocytopenia were observed in $12 \%$ and $7 \%$ of patients, respectively, and grade $2 / 3$ fatigue was observed in $18 \%$ of patients. This Phase I/II study demonstrated the feasibility of a modified platinum-doublet regimen as a treatment option for patients $\geq 70$ years with squamous NSCLC; however, toxicity remains an important factor for this patient subset. The current analysis of nab-paclitaxel/carboplatin vs paclitaxel/carboplatin treatment of patients $\geq 70$ years of age with squamous histology from the Phase III trial adds to the limited body of knowledge on safe and effective first-line platinum-doublet options for this patient population.

Recently, immunotherapy has emerged as a treatment option for patients with advanced NSCLC, including those with squamous histology. ${ }^{20-22}$ However, data for patients $\geq 70$ years treated with these agents in the first line are limited and based only on retrospective analyses of the main trials. Some early insights can be gleaned from a recent Phase III trial evaluating pembrolizumab vs investigator's choice of platinum-based chemotherapy $(n=305)$ in patients with metastatic NSCLC and PD-L1 expression on at least $50 \%$ of tumor cells with no EGFR or ALK mutations. ${ }^{23}$ In the trial, pembrolizumab treatment was associated with a survival benefit vs platinum-based chemotherapy in most patient subgroups, including patients aged $\geq 65$ years and those with squamous histology. Although safety data were not reported for these patient subsets, grade $\geq 3$ treatmentrelated adverse events in the overall population were less frequent with pembrolizumab vs platinum-based chemotherapy
(27\% vs 53\%). Additional prospective studies are needed to evaluate immunotherapeutic agents as first-line treatment of elderly patients with squamous NSCLC.

Although these results support the use of nab-paclitaxel/ carboplatin in elderly patients with squamous histology, it is important to note the limitations associated with this analysis. This was a post hoc evaluation, which could have introduced statistical bias. Furthermore, this analysis included a small number of patients; therefore, the results should be interpreted with caution. In addition, this analysis did not factor in the use of second-line treatment, which could have affected OS outcomes in these patients. Prospective data are needed to confirm the results described here.

\section{Conclusion}

The results of this analysis suggest that nab-paclitaxel/ carboplatin is an effective treatment option for patients $\geq 70$ years with squamous NSCLC. In this retrospective analysis, nab-paclitaxel/carboplatin was more efficacious than paclitaxel/carboplatin, resulting in a greater ORR, longer OS, and favorable toxicity. These findings are consistent with those observed in the ITT population and with those in a subset from the previously published Phase III trial.

\section{Clinical practice points}

- Treatment of elderly patients with advanced NSCLC is challenging due to comorbidities and concerns about increased toxicity. Although some evidence suggests that outcomes may be worse for elderly patients with squamous histology than for other histological subtypes, the impact of histology on treatment outcomes in this patient population remains to be fully investigated.

- nab-Paclitaxel combined with carboplatin is approved for the first-line treatment of locally advanced or metastatic NSCLC, including elderly patients and those with squamous histology.

- This retrospective analysis from the Phase III registrational trial demonstrated that nab-paclitaxel/carboplatin resulted in longer survival and was well tolerated compared with paclitaxel/carboplatin in patients $\geq 70$ years with squamous NSCLC.

- These results also align with previously reported outcomes observed in the Phase III ITT population and with data published separately for the elderly and squamous subsets. Future studies will provide insight on whether a nab-paclitaxel-based regimen is suitable for combination with immunotherapy agents in this patient population. 


\section{Acknowledgments}

Medical writing assistance was provided by Dena Jacob, $\mathrm{PhD}$, MediTech Media, Ltd, funded by Celgene Corporation. The authors were fully responsible for all content and editorial decisions for this manuscript. This work was supported by Celgene Corporation.

\section{Disclosure}

TC, AK, TJO: employment or leadership position and stock ownership, Celgene Corporation. MEO: advisory role, Celgene, GSK, BMS, Pierre Fabre, Medimmune, MSD, Pfizer, Daichii Sankyo. MAS: honoraria and speaker's bureau, Celgene. PEP: advisory board member of Celgene, Boehringer Ingelheim, Halozyme, Teva, Clovis Oncology, Eli Lilly. The authors report no other conflicts of interest in this work.

\section{References}

1. Surveillance, Epidemiology, and End Results Program. SEER stat fact sheets: lung and bronchus cancer; 2016. Available from: https://seer. cancer.gov/statfacts/html/lungb.html. Accessed January 25, 2018.

2. Gajra A. Defining the issues in the treatment of elderly patients with advanced non-small-cell lung cancer. Lung Cancer Manage. 2015;4(1): 17-30.

3. Quoix E. Optimal pharmacotherapeutic strategies for elderly patients with advanced non-small cell lung cancer. Drugs Aging. 2011;28(11): 885-894.

4. Gridelli C, Brodowicz T, Langer CJ, et al. Pemetrexed therapy in elderly patients with good performance status: analysis of two phase III trials of patients with nonsquamous non-small-cell lung cancer. Clin Lung Cancer. 2012;13(5):340-346.

5. Socinski MA, Langer CJ, Okamoto I, et al. Safety and efficacy of weekly $\mathrm{nab}^{\circledR}$-paclitaxel in combination with carboplatin as first-line therapy in elderly patients with advanced non-small-cell lung cancer. Ann Oncol. 2013;24(2):314-321.

6. Gridelli C. The ELVIS trial: a phase III study of single-agent vinorelbine as first-line treatment in elderly patients with advanced non-small cell lung cancer. Elderly Lung Cancer Vinorelbine Italian Study. Oncologist. 2001;6(Suppl 1):4-7.

7. Gridelli C, Perrone F, Gallo C, et al; MILES Investigators. Chemotherapy for elderly patients with advanced non-small-cell lung cancer: the Multicenter Italian Lung Cancer in the Elderly Study (MILES) phase III randomized trial. J Natl Cancer Inst. 2003;95(5):362-372.

8. Novello S, Barlesi F, Califano R, et al. Metastatic non-small-cell lung cancer: ESMO clinical practice guidelines for diagnosis, treatment and follow-up. Ann Oncol. 2016;27(Suppl 5):v1-v27.

9. Masters GA, Temin S, Azzoli CG, et al; American Society of Clinical Oncology Clinical Practice. Systemic therapy for stage IV non-small-cell lung cancer: American Society of Clinical Oncology clinical practice guideline update. J Clin Oncol. 2015;33(30):3488-3515.
10. The National Comprehensive Cancer Network. NCCN clinical practice guidelines in oncology: non-small cell lung cancer; 2018. Version 2.2018. Available from: https://www.nccn.org/professionals/ physician_gls/pdf/nscl.pdf. Accessed January 25, 2018.

11. Owonikoko TK, Ragin CC, Belani CP, et al. Lung cancer in elderly patients: an analysis of the Surveillance, Epidemiology, and End Results database. J Clin Oncol. 2007;25(35):5570-5577.

12. Cetin K, Ettinger DS, Hei YJ, O’Malley CD. Survival by histologic subtype in stage IV nonsmall cell lung cancer based on data from the Surveillance, Epidemiology and End Results program. Clin Epidemiol. 2011;3:139-148.

13. Socinski MA, Bondarenko I, Karaseva NA, et al. Weekly nab-paclitaxel in combination with carboplatin versus solvent-based paclitaxel plus carboplatin as first-line therapy in patients with advanced non-smallcell lung cancer: final results of a phase III trial. J Clin Oncol. 2012; 30(17):2055-2062.

14. Socinski MA, Okamoto I, Hon JK, et al. Safety and efficacy analysis by histology of weekly nab-paclitaxel in combination with carboplatin as first-line therapy in patients with advanced non-small-cell lung cancer. Ann Oncol. 2013;24(9):2390-2396.

15. Karampeazis A, Vamvakas L, Kentepozidis N, et al. Biweekly carboplatin plus gemcitabine as first-line treatment of elderly patients with advanced squamous non-small-cell lung cancer: a multicenter phase I-II trial by the Hellenic Oncology Research Group. Clin Lung Cancer. 2016; 17(6):543-549.

16. Langer CJ, Hirsh V, Ko A, Renschler MF, Socinski MA. Weekly nab-paclitaxel in combination with carboplatin as first-line therapy in patients with advanced non-small-cell lung cancer: analysis of safety and efficacy in patients with renal impairment. Clin Lung Cancer. 2015; 16(2):112-120.

17. Hirsh V,Ko A, PilotR, RenschlerMF, SocinskiMA. Weekly nab-paclitaxel in combination with carboplatin as first-line therapy in patients with advanced non-small-cell lung cancer: analysis of safety and efficacy in patients with diabetes. Clin Lung Cancer. 2016;17(5):367-374.

18. Quoix E, Zalcman G, Oster JP, et al; Intergroupe Francophone de Cancérologie Thoracique. Carboplatin and weekly paclitaxel doublet chemotherapy compared with monotherapy in elderly patients with advanced non-small-cell lung cancer: IFCT-0501 randomised, phase 3 trial. Lancet. 2011;378(9796):1079-1088

19. Thatcher N, Hirsch FR, Luft AV, et al; SQUIRE Investigators. Necitumumab plus gemcitabine and cisplatin versus gemcitabine and cisplatin alone as first-line therapy in patients with stage IV squamous non-small-cell lung cancer (SQUIRE): an open-label, randomised, controlled phase 3 trial. Lancet Oncol. 2015;16(7):763-774.

20. Opdivo (nivolumab) Injection, for intravenous use [prescribing information]. Princeton, NJ, USA: Bristol-Myers Squibb; 2018.

21. Keytruda (pembrolizumab) Injection, for intravenous use [prescribing information]. Whitehouse Station, NJ, USA: Merck \& Co, Inc; 2017.

22. Tecentriq (atezolizumab) Injection, for intravenous use [prescribing information]. South San Francisco, CA, USA: Genentech, Inc; 2017.

23. Reck M, Rodriguez-Abreu D, Robinson AG, et al; KEYNOTE-024 Investigators. Pembrolizumab versus chemotherapy for PD-L1-positive non-small-cell lung cancer. $N$ Engl J Med. 2016;375(19):1823-1833.

\section{Publish your work in this journal}

Drug Design, Development and Therapy is an international, peerreviewed open-access journal that spans the spectrum of drug design and development through to clinical applications. Clinical outcomes, patient safety, and programs for the development and effective, safe, and sustained use of medicines are the features of the journal, which

\section{Dovepress}

has also been accepted for indexing on PubMed Central. The manuscript management system is completely online and includes a very quick and fair peer-review system, which is all easy to use. Visit http://www.dovepress.com/testimonials.php to read real quotes from published authors. 